\title{
Immunomodulatory Effect of Charak Immunity Tablets (CIT) on Healthy Participants: A single blind, randomized, placebo-controlled, exploratory study
}

\author{
Akanksha Mourya ${ }^{1}$, Amit Yadav ${ }^{1}$, Suresh Khadke ${ }^{1}$, Sarika Mane ${ }^{1}$, Asavari Joshi ${ }^{1}$, Poonam Gupte ${ }^{1}$, \\ Madhavi Mahajan ${ }^{2}$ and Supriya Bhalerao ${ }^{1 *}$

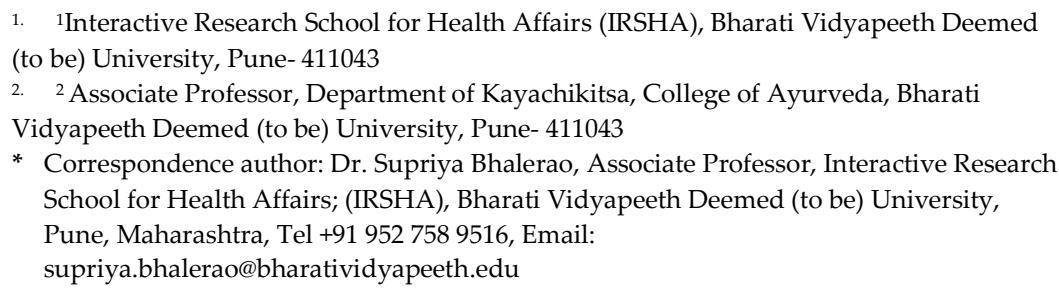

Abstract: Immunity has become an important aspect of concern, as the spread of corona virus, is on the rise. The strategies to boost and modulate the immunity have therefore become need of the hour. The present study was carried out to evaluate the effect of Charak immunity Tablets (CIT) on innate and adaptive immune response in healthy individuals. It was a single-blind, randomized, placebo-controlled, exploratory study. After obtaining Ethics Committee permission, 36 healthy individuals of either sex aged 18-35 years with prior consent were recruited in the study. They were randomly divided into 2 groups to receive either CIT or Placebo in 2:1 ratio. Both the interventions were given in a dose of $1 \mathrm{tab}$ (500 mg) twice daily. The assessment variables were vitals [temperature, pulse, and blood pressure], respiratory health [respiratory rate, oxygen saturation and peak expiratory flow rate], questionnaire based assessment of immune status, perceived stress and quality of life along with objective assessment of immunity [CD4+, CD8+ counts, Interferon gamma (IFN $\gamma)$, Tumor necrosis factor alpha (TNF- $\alpha$ ) and Interleukin 10 (IL-10)] as well as oxidative stress; [Malondialdehyde (MDA) and Glutathione peroxidase], which were assessed at fixed time points. Of 36 recruited participants, only 18 participants completed the study. CIT treated individuals showed a statistically significant improvement in respiratory health, quality of life, perceived stress and subjective immune status. There was a decrease in the levels of serum IFN $\gamma$ on day 60 compared to baseline. TNF- $\alpha$ and IL-10, both estimated from supernatant of Peripheral Blood Mononuclear Cells (PBMCs) stimulated with lipopolysaccharide (LPS), showed a decrease and a significant increase respectively on day 60 compared to baseline in CIT group. Further, CIT significantly decreased MDA levels.

The present study indicates that CIT is an effective and safe drug to boost immunity. However, our findings need to be confirmed in larger sample size using more specific immune parameters.

Keywords: CD4- CD8 counts; immunity; inflammation; oxidative stress; peak expiratory flow rate

\section{Introduction}


Immune system is a complex network of organs, tissues, cells, and body processes that provide resistance to infection and toxins..$^{[1]}$ The pressure that natural selection exerts on immune system is infinite and never-ending. Emerging infectious diseases have potential to generate an enormous variety of cells and molecules capable of specifically recognizing and eliminating an apparently limitless variety of foreign invaders. ${ }^{[2,3]}$ The evolution of immune system has undergone incredible selective pressure imposed by wide array of pathogens. The two main activities on which immune system works, despite of all differences, is recognition and response towards any interacted pathogen, i.e. through innate and adaptive immune response. ${ }^{[4,5]}$ These immune responses involve secretion and activation of various cells like dendritic cells, macrophages, neutrophils, natural killer cells, B-cells \& T-cells, cytokines like Tumor necrosis factors, interleukins, interferons, and protein molecules.[6,7] Factors like, age, medication, infections, stress affect immune homeostasis by altering the immune regulatory network leading to decreased responsiveness by the system. ${ }^{[8-12]}$ Several other studies have also validated that lack of immunological activation markers and receptors, oxidative damage (ROS production), reduced antioxidant potential can also hamper efficiency of immune system. ${ }^{[13-15]}$

Emergence of COVID-19 has highlighted the importance of the immune system ${ }^{[16]}$ and as a result, various strategies and approaches are being implemented to improve and modulate immune system, reduce disease aggravation in patients and stimulate profound response in healthy individuals.[17] As the world turns to science in search of an effective drug or vaccine, countries, such as India and China, with heritage of using traditional medicine ${ }^{[18,19]}$ have also begun to explore the role of traditional and complementary treatment. Ayurveda, the traditional Indian system of medicine has enlisted medicinal herbs like Withania somnifera L (Ashwagandha),[20] Tinospora cordifolia (Guduchi), Asparagus racemosus (Shatavari), Phyllanthus emblica (Amalaki), which have been validated for their immunomodulatory activities. ${ }^{[8,21]}$ Several in-vitro studies are also suggestive that herbal drugs can target various cell subsets of immune system like neutrophils, macrophages, and lymphocytes and also modulate the cytokine secretion in lipopolysaccharide (LPS) stimulated cells to enhance the functioning of system. ${ }^{[22-25]}$

CIT (Charak immunity tablets), a patent and proprietary Ayurvedic formulation of Charak Pharma Pvt. Ltd. is composed of powder of Triphala Guggul (200mg) and extracts of Tinospora cordifolia (500mg), Curcuma longa L(500 mg), Rubia cordifolia L(250mg), Plumbago zeylanica L(150mg) and Piper longum L, Piper nigrum L, Zingiber officinale Roscoe, each weighing $66.66 \mathrm{mg}$. A majority of these ingredients have been reported for their immunomodulatory, antioxidant and antiinflammatory activities.[26-30] With this background, the present study was designed to assess the effect of CIT on immunity.

\section{Material and Methods:}

Ethical consideration:

The study was approved by Institutional Ethics Committee (BVDUCOA/EC/2829/2020-2021) and registered prospectively with Clinical Trial Registry of India (CTRI/2017/07/008999). 
A single-blind, randomized, placebo controlled, exploratory study.

Sample Size:

This was an exploratory study so a sample size of 30 completed participants (20 in CIT group and 10 in Placebo group) was considered adequate. Considering a 20\% attrition rate, a total of 36 individuals were recruited.

Screening and Recruitment of Healthy Individuals:

The study was conducted during the period January 2021- May 2021. Individuals in the age group of 18-35 years of either sex without any medical, surgical history, severe cardiac, renal, or liver pathologies were screened for blood investigations viz. Haemogram [Hemoglobin $(\mathrm{Hb})$, Erythrocyte Sedimentation Rate (ESR), Platelets, White blood cells (WBC count)], Fasting blood glucose (FBG), Liver function tests [LFTserum glutamic oxaloacetic transaminase (SGOT) and serum glutamic pyruvic transaminase (SGPT)] and renal function test (serum creatinine). Individuals with hemoglobin levels $\leq 9 \mathrm{~g} \%$, LFT and RFT levels greater than 2.5 times and 1.5 times, the upper normal limit respectively, while rest of the investigations beyond normal reference ranges, were excluded from the study. Individuals with a history of consumption of herbal/ nutritional/ pre and probiotic supplements/ multivitamins/ or available marketed medications for immunity for the past 30 days were excluded. Lactating and pregnant women were also not considered for the study.

At baseline, all individuals were subjected to examination of vitals (temperature, pulse, and blood pressure), respiratory health [respiratory rate, oxygen saturation $\left(\mathrm{SpO}_{2}\right)$, and peak expiratory flow rate (PEFR)].

Standardized and validated questionnaires namely immune status questionnaire (ISQ), perceived stress scale (PSS) and WHOQOL-BREF (World Health Organization Quality of life) were administered to the participants to assess their immunity, perceived stress and quality of life respectively. ISQ comprises of 7 questions which gives a maximum score of 10. This score denotes good immune health of the individual, while a score of 0 indicates poor immune health. ${ }^{[31]}$ PSS has 10 questions. The maximum score that can be obtained by an individual is 40 and it indicates severe stress in the person, while a score of 0 is indicative of the person being stress free. ${ }^{[32]}$ The WHOQOL-BREF consists of 26 questions divided over four domains viz. physical health, physiological health, social relationship, and environment. The measure of quality of life is calculated by summing the point values for the question corresponding to each domain and then transforming the scores to 0-100-point interval. Higher the points, better the quality of life of that individual. [33]

This was followed by blood collection $(12 \mathrm{ml})$ for the estimation of immune and oxidative stress parameters. Subsequently, the participants were randomized to two groups viz. CIT and Placebo in the ratio of 2:1. Initially the study interventions were provided for a period of first 30 days. On day 30, the participants were followed up and examined for vitals, respiratory health along with subjective assessment of immunity, stress and quality of life using the above mentioned questionnaires. The participants were provided with medicines for further 30 days and called on day 60. Above mentioned clinical as well as questionnaire based parameters were also done on day 60. Participants were 
telephonically followed up on $15^{\text {th }}$ and $45^{\text {th }}$ day to enquire about their health and to ensure compliance.

\section{Study Intervention and Dosage:}

Both interventional drugs, CIT \& Placebo were supplied by Charak Pharma Pvt. Ltd. The size, color, shape and packaging of both CIT and Placebo were identical to avoid identification by participants.

Placebo was composed of maize starch $(205 \mathrm{mg})$ as the main ingredient along with potassium sorbate $(1.3 \mathrm{mg})$, sorbic acid $(0.15 \mathrm{mg})$, sodium benzoate $(0.49 \mathrm{mg})$, calcium stearate $(1 \mathrm{mg})$, colloidal silicon dioxide (10mg), sodium crosscarmellose (20 mg), crospovidone (40mg) and coating mix $(28.8 \mathrm{mg})$.

Both the tablets, CIT \& Placebo were administered in the dose, 1 tablet (500mg each) twice a day after meals with water for a total duration of 2 months.

\section{Blood Sampling and Processing:}

Blood collection was done through closed collection procedure to minimize contamination. Of the $12 \mathrm{ml}$ blood collected at baseline, $1.5 \mathrm{ml}$ blood was processed for flow cytometry based estimation of immunological surface markers (CD4+ and CD8+). Nine ml blood was processed to isolate PBMCs and RBCs. Remaining $1.5 \mathrm{ml}$ blood was centrifuged to obtain serum for estimating serum IFN- $\gamma$. On day 30, only $1.5 \mathrm{ml}$ blood was taken for assessment of serum IFN- $\gamma$. On day 60, in addition to $12 \mathrm{ml}$ blood collected at baseline, $3 \mathrm{ml}$ blood (total $15 \mathrm{ml}$ ) was collected for estimation of parameters carried out during screening except fasting glucose.

Cytokine estimation from stimulated PBMCs:

Briefly, blood $(9 \mathrm{ml})$ was subjected to density gradient centrifugation using histopaque [(1:2 in phosphate buffered saline (PBS)] to separate PBMCs and RBCs. Isolated PBMCs in the density $5 \times 10^{5}$ were cultured in each well and seeded in RPMI 1640 medium (HiMedia) for $2 \mathrm{~h}$. Later, the cells were stimulated with Escherichia coli derived lipopolysaccharide (LPS- Sigma Aldrich) at the concentration of $0.5 \mu \mathrm{g} / \mathrm{ml}$ and incubated for $4 \mathrm{~h}$, at $37{ }^{\circ} \mathrm{C}$ in $5 \% \mathrm{CO}_{2}$ incubator. The culture supernatant was harvested for the estimation of cytokines viz. TNF- $\alpha$, IL-10. The cytokines were estimated using commercially available ELISA kits [Biolegend].

\section{Oxidative stress estimation from RBCs:}

Malondialdehyde (MDA) was quantified from RBCs using Thiobarbituric acid reactive substances (TBARS) method described as per Kanias et al.[34] The method is based on the acidic reaction of MDA with thiobarbituric acid, which forms a (TBARS) chromophore which is absorbed at $532 \mathrm{~nm}$. Glutathione peroxidase (GPx) levels from the RBCs lysate (1:10 diluted in phosphate buffer) were measured using commercially available colorimetric assay kit (Cayman, US). The method is based on coupled reaction with glutathione reductase and nicotinamide adenine dinucleotide phosphate (NADPH) which is accompanied by decreased absorbance at 340nm. This rate of decrease is directly proportional to the amount of GPx present inside the cell. 


\section{Statistical Analysis:}

The parametric data is presented as Mean \pm SD and analyzed using paired or unpaired $t$ test and repeated measures ANOVA test. The nonparametric data is presented as Median (Range) and analyzed using Wilcoxan Rank sum test /Mann Whitney test and Friedman's test. Tukey's post hoc test was applied where applicable. GraphPad InStat software, version 9 was used to perform the analysis. $p<0.05$ was considered as level of statistical significance.

\section{Results:}

A total of 45 individuals were screened, of which 36 healthy individuals were recruited. Only 18 individuals completed the study. This attrition was mainly because of rise in COVID-19 pandemic throughout the city and implementation of subsequent lockdown, which occurred during the course of the study. The detailed participant flow is given in Figure 1.

\section{Figure 1: Flowchart of study participants}

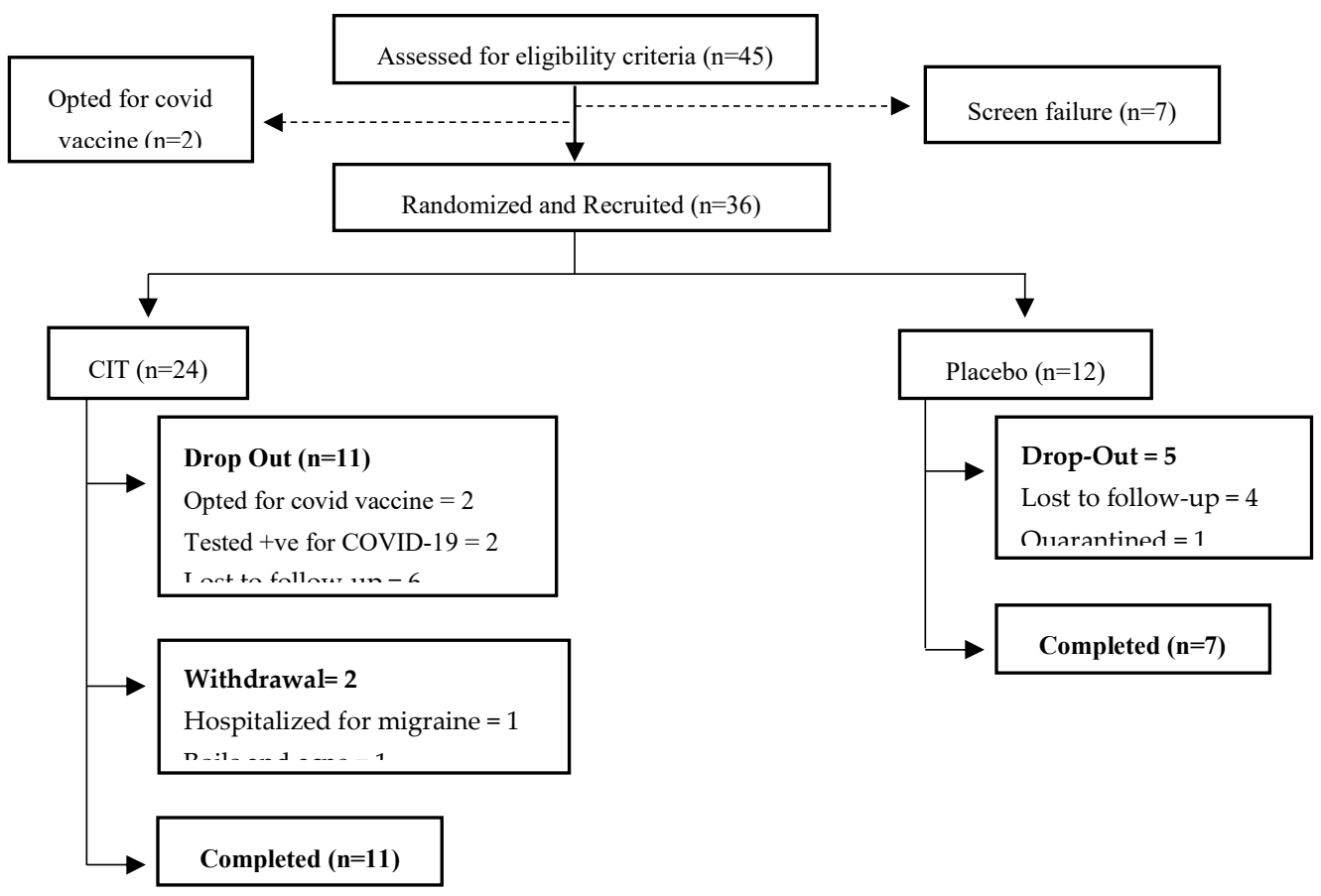

The male to female ratio of completed participants in the CIT group was $6: 5$ while that in the placebo group was $4: 3$. The mean age of the participants in CIT group was $22.9 \pm 3.7$ while that in placebo group was $23.3 \pm 5.9$. The distribution of participants as well as their age in both groups was comparable.

The vitals and parameters indicating respiratory health were in normal range post the study. There was a gradual increase noted in PEFR in CIT group, which was statistically significant $(\mathrm{p}<0.05)$ on day 60 compared to baseline. No such increase was seen in placebo group (Table 1). 
Table 1: Effect of CIT on Vitals and Respiratory Health

\begin{tabular}{|c|c|c|c|c|c|c|}
\hline \multirow[t]{2}{*}{ Parameters } & \multicolumn{3}{|c|}{ CIT group $(n=11)$} & \multicolumn{3}{|c|}{ Placebo group $(n=7)$} \\
\hline & Day 0 & Day 30 & Day 60 & Day 0 & Day 30 & Day 60 \\
\hline $\begin{array}{l}\text { Temperature } \\
\left({ }^{0} \mathrm{C}\right)\end{array}$ & $36.2 \pm 0.1$ & $36.3 \pm 0.1$ & $36.2 \pm 0.2$ & $36.4 \pm 0.2$ & $36.4 \pm 0.1$ & $36.3 \pm 0.1$ \\
\hline $\begin{array}{l}\text { Pulse } \\
(/ \text { min })\end{array}$ & $77 \pm 4.9$ & $79.5 \pm 7.9$ & $78.5 \pm 4.3$ & $82.3 \pm 7.1$ & $80.3 \pm 9.1$ & $79.3 \pm 7.5$ \\
\hline $\begin{array}{l}\text { BP- Systolic } \\
\text { (mm Hg) }\end{array}$ & $\begin{array}{ll}115.8 & \pm \\
14.2 & \\
\end{array}$ & $\begin{array}{ll}115.6 \quad \pm \\
12.6\end{array}$ & $\begin{array}{ll}117.5 & \pm \\
5.1 & \\
\end{array}$ & $\begin{array}{l}110.1 \\
13.1\end{array}$ & $\begin{array}{ll}109 & \pm \\
15.3 & \\
\end{array}$ & $\begin{array}{ll}112.3 \quad \pm \\
12.4\end{array}$ \\
\hline $\begin{array}{l}\text { BP-Diastolic } \\
(\mathrm{mm} \mathrm{Hg})\end{array}$ & $83.9 \pm 15.5$ & $78.9 \pm 10.4$ & $83.7 \pm 4$ & $71 \pm 10.2$ & $71.4 \pm 9.2$ & $76.9 \pm 10.9$ \\
\hline $\begin{array}{l}\text { Respiratory } \\
\text { rate (/min) }\end{array}$ & $19.5 \pm 1.4$ & $19.9 \pm 2$ & $19.8 \pm 1.1$ & $20.5 \pm 1.8$ & $20.1 \pm 2.2$ & $21.5 \pm 2.2$ \\
\hline $\mathrm{SpO} 2(\%)$ & $97.2 \pm 1.4$ & $96.9 \pm 1.3$ & $97.9 \pm 0.7$ & $96 \pm 1.6$ & $97.3 \pm 1$ & $97.1 \pm 0.9$ \\
\hline PEFR (lit/min) & $\begin{array}{l}298.2 \\
78.7\end{array}$ & $\begin{array}{l}310.9 \\
69.9\end{array}$ & $\begin{array}{c}337 \\
50 *\end{array}$ & $\begin{array}{l}290.9 \\
115.9\end{array}$ & $\begin{array}{ll}284.8 & \pm \\
110.9 & \end{array}$ & $\begin{array}{l}297.7 \\
131.2\end{array}$ \\
\hline
\end{tabular}

${ }^{*} \mathrm{p}<0.05$ as compared to day 0 using repeated measures ANOVA followed by Tukey's post hoc test

In CIT group, the immune status was found significantly improved on day 60 as compared to its baseline as well as placebo group. There has been a gradual decrease in levels of stress in CIT Group, with a significant reduction on day $60(\mathrm{p}=0.007)$ as compared to baseline; whereas in the placebo group, an increase in stress levels was observed. There was an increase in scores of all four domains of quality of life in CIT group on day 60 with a significant increase in physical $(\mathrm{p}=0.0015)$ and environmental ( $p=0.0157)$ domain. In placebo group, the increase in scores was seen only in 2 domains, which was not significant statistically. (Table 2).

Table 2: Effect of CIT on clinical assessments

\begin{tabular}{|l|l|l|l|l|l|l|}
\hline \multirow{2}{*}{ Parameters } & \multicolumn{3}{|c|}{ CIT group (n=11) } & \multicolumn{3}{c|}{ Placebo group (n=7) } \\
\cline { 2 - 7 } & \multicolumn{1}{|c|}{ Day 0 } & \multicolumn{1}{|c|}{ Day 30 } & \multicolumn{1}{c|}{ Day 60 } & \multicolumn{1}{c|}{ Day 0 } & \multicolumn{1}{c|}{ Day 30 } & \multicolumn{1}{c|}{ Day 60 } \\
\hline Immune status & $8(6-9)$ & $9(6-10)$ & $10^{* \#}(7-10)$ & $7(6-10)$ & $8(6-10)$ & $8(6-10)$ \\
\hline $\begin{array}{l}\text { Perceived } \\
\text { stress }\end{array}$ & $18(7-34)$ & $15(9-30)$ & $14^{*}(7-26)$ & $13(7-32)$ & $18(12-30)$ & $16(10-29)$ \\
\hline Quality of life & \multicolumn{7}{|l|}{} & & & \\
\hline Physical health & 70 & 81 & $85^{* *}$ & 75 & 81 & 85 \\
& $(63-100)$ & $(70-94)$ & $(72-99)$ & $(69-86)$ & $(69-100)$ & $(69-10)$ \\
\hline $\begin{array}{l}\text { Physiological } \\
\text { health }\end{array}$ & 75 & 75 & 80 & 81 & 81 & 84 \\
\hline $\begin{array}{l}\text { Social } \\
\text { relationship }\end{array}$ & $\begin{array}{l}76-96) \\
(56-94)\end{array}$ & $(58-94)$ & $(56-89)$ & $(56-88)$ & $(75-86)$ \\
\hline Environment & 75 & 83 & 81 & 75 & 65 \\
& $(63-89)$ & $(35-94)$ & $(50-86)$ & $(50-100)$ & $(31-94)$ & $(40-96)$ \\
\hline
\end{tabular}

$* \mathrm{p}<0.05, * * \mathrm{p}<0.01$ compared to day 0 using Friedman test

${ }^{\#} \mathrm{p}<0.05$ compared to placebo on day 60 using Mann Whitney test 
Irrespective of the study groups, hematological parameters as well as SGOT, SGPT and serum creatinine remained in the normal range at the end of the study and did not show any statistically or clinically significant change.

It was observed that on day 60 the CD4+ counts did not show much change compared to baseline, while CD8+ counts reduced irrespective of the group. This decrease was not statistically significant. Owing to the drop in CD8 counts, CD4:CD8 ratio was found to be significantly ( $\mathrm{p}<$ 0.01 ) increased in both the groups (Table 3).

Table 3: Effect of CIT on CD4 \& CD8 Cells

\begin{tabular}{|l|l|l|l|l|}
\hline \multirow{2}{*}{ Parameters } & \multicolumn{2}{|c|}{ CIT group (n=11) } & \multicolumn{2}{c|}{ Placebo group $(\mathbf{n}=7)$} \\
\cline { 2 - 5 } & \multicolumn{1}{|c|}{ Day 0 } & \multicolumn{1}{c|}{ Day 60 } & \multicolumn{1}{c|}{ Day 0 } & \multicolumn{1}{c|}{ Day 60 } \\
\hline $\mathrm{CD} 4($ cells $/ \mu \mathrm{l})$ & $879.4 \pm 262.4$ & $879.2 \pm 293.5$ & $992.7 \pm 165.2$ & $943 \pm 319.3$ \\
\hline $\mathrm{CD} 8($ cells $/ \mu \mathrm{l})$ & $887.9 \pm 417.3$ & $704.8 \pm 277.3$ & $752.6 \pm 226.3$ & $583.9 \pm 276.6$ \\
\hline $\mathrm{CD} 4: \mathrm{CD} 8$ & $1.1 \pm 0.36$ & $1.3 \pm 0.39 * *$ & $1.45 \pm 0.49$ & $1.73 \pm 0.57 * *$ \\
\hline
\end{tabular}

$* * \mathrm{p}<0.01$ compared to day 0 using Paired t test

Median levels of serum IFN- $\gamma$ in the CIT group on day 30 were observed to be increased compared to baseline which later got reduced on day 60 with no statistically significant difference, whereas in Placebo group on day 30, the levels decreased followed by increase on day 60 (Figure 2).

Figure 2: Effect of CIT on IFN- $\gamma$

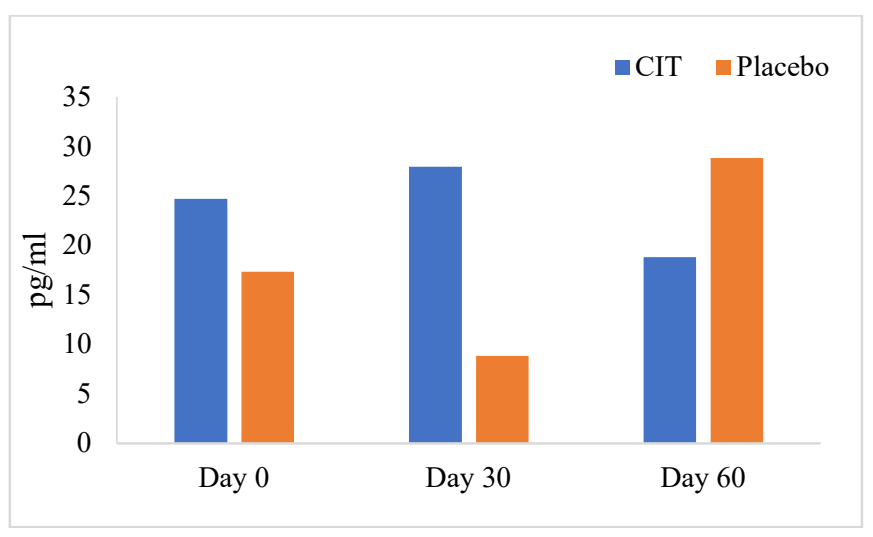

CIT group showed reduction in TNF- $\alpha$ levels in LPS stimulated PBMCs while in placebo group the levels increased on day 60 compared to day 0 . There was no statistical difference observed in the levels of TNF- $\alpha$ within or between groups. IL-10 levels in LPS stimulated PBMCs were found to be increased in both groups on day 60 as compared to day 0 with a statistical significance $(\mathrm{p}=0.0007)$ observed in CIT group. (Figure 3).

Figure 3: Effect of CIT on TNF- $\alpha$ \& IL-10 in LPS stimulated PBMCs 


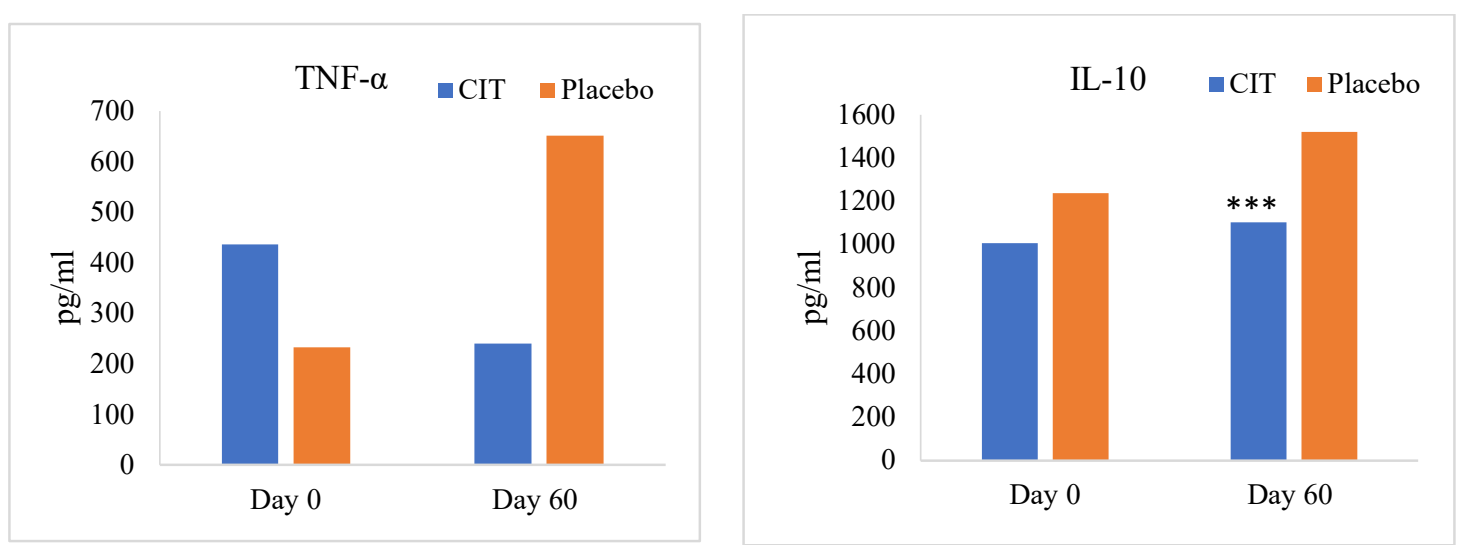

$* * * \mathrm{p}<0.001$ compared to day 0 in CIT group using Wilcoxan Rank- Sum test

The MDA levels in CIT group significantly $(p=0.0189)$ decreased on day 60 compared to baseline; while in placebo group, the MDA levels increased on day 60. The median GPx levels in both the groups exhibited increase on day 60 as compared to day 0 (Table 4 ).

Table 4: Effect of CIT on MDA and GPx

\begin{tabular}{|l|l|l|l|l|}
\hline \multirow{2}{*}{ Parameters } & \multicolumn{2}{|c|}{ CIT group $(\mathbf{n}=11)$} & \multicolumn{2}{c|}{ Placebo group $(\mathbf{n}=7)$} \\
\cline { 2 - 5 } & \multicolumn{1}{|c|}{ Day 0 } & \multicolumn{1}{c|}{ Day 60 } & \multicolumn{1}{c|}{ Day 0 } & Day 60 \\
\hline MDA $(\mathrm{mmol} / \mathrm{ml})$ & $5.01 \pm 2.24$ & $3.48 \pm 1.49^{*}$ & $2.85 \pm 1.42$ & $3.20 \pm 1.21$ \\
\hline $\mathrm{GPx}$ & 1339.7 & 1589.3 & 1151.2 & 1377.9 \\
$(\mathrm{nmol} / \mathrm{min} / \mathrm{ml})$ & $(264.9-2760.9)$ & $(387.1-4604.9)$ & $(860.9-1619.8)$ & $(407.5-1818.5)$ \\
\hline
\end{tabular}

${ }^{*} \mathrm{p}<0.05$ compared to day 0 using Paired $\mathrm{t}$ test

\section{Discussion:}

The present clinical study aimed to evaluate the immunomodulatory effects of Charak immunity tablets (CIT). We observed a significant increase in Peak expiratory flow rate compared to baseline in CIT group. CIT significantly improved questionnaire based assessment parameters viz. immune status, quality of life and perceived stress. There was an increase in the serum IFN $\gamma$ levels on day 30 followed by a decrease on day 60. The levels of TNF- $\alpha$ (proinflammatory cytokine) reduced in CIT group along with a significant increase in the levels of IL-10 (anti-inflammatory cytokine) at the end of the study. The oxidative stress (MDA) levels too showed a significant decrease in CIT group compared to baseline. The parameters haemogram, SGOT, SGPT and serum creatinine remained within their normal reference ranges at the end of the study indicative of the safety of drug CIT.

CIT is a polyherbal formulation that consists of herbs with known immunomodulatory activities. In the present study, we evaluated its effect using a wide array of parameters. Peak Expiratory Flow Rate (PEFR) is a simple indicator of lung capacity. ${ }^{[35]}$ We carried out the study during the COVID-19 pandemic. The decreased lung capacity in individuals infected with SARS-CoV-2 is well reported. ${ }^{[36,37]}$ On this background, a significant increase in the PEFR after CIT administration seen in our study participants is important.

CIT also showed significant improvement in parameters assessed by different questionnaires. We assessed immune status of the study participants using Immune Status Questionnaire, which gives an idea 
about self-perception of the health status. Our study showed a significant increase in immune status after CIT treatment compared to baseline as well as placebo suggestive of a positive effect of CIT. Further, we measured the perceived stress levels of the study participants pre- and-post intervention. The profound effect of physiological factors like stress on immune system is well known. ${ }^{[12]} \mathrm{A}$ moderate level of stress impacting mental health of general population during the quarantine period of COVID has been reported. [38,39] Through the concept of psycho neuro endocrine immune (PNEI) axis the link between psychological and physical health is well established. ${ }^{[40]}$ The association of PNEI axis with negative impacts of SARS-CoV-2 infection has also been reported lately. ${ }^{[41]}$ We observed a significant decrease in stress levels in CIT group on day 60. Thus, the decreased stress levels are suggestive of improved immunity. Further, it is seen that many social, environmental, lifestyle factors promote pathology of systemic chronic inflammation in our body leading to disorders which result in reduced immune functioning and subsequently have a negative impact on wellbeing and quality of life. ${ }^{[42]} \mathrm{A}$ handful of studies done during this pandemic situation have shown reduction of scores in different domains pertaining to quality of life. ${ }^{[43-45]}$ In our study, CIT improved scores in all the 4 domains of QOL, suggestive of better quality of life despite a harsh social crisis such as COVID.

Apart from the questionnaires, we studied the effect of CIT on different cells involved in immune responses. CD4+ $\mathrm{T}$ cells ( $\mathrm{T}$ helper cells) are involved in elimination of pathogens as part of adaptive immune response along with regulation of the cytokine secretion. ${ }^{46]}$ Monitoring the levels of CD4+ is thereby essential to understand the extent of immune status and its role in development of immune response. ${ }^{[47]}$ These cells are also critical for the generation of high-affinity memory B cells, long-lived plasma cells, and memory CD8+ T cells. ${ }^{[48]}$ On the other hand CD8+ cells are surface markers for cytotoxic $\mathrm{T}$ lymphocytes which are critically important in cell mediated immunity to confront virally infected cells through endogenous antigen presentation. ${ }^{[3]}$ This makes them essential for maintaining protective immunity to many classes of infectious pathogens. ${ }^{[48]}$ Further, the effects of psychological stress on immune functions have also been observed, which include decreased percentages of CD4 helper T cells and CD8 cytotoxic $\mathrm{T}$ cells along with other factors. ${ }^{[49]} \mathrm{CD} 4 / \mathrm{CD} 8$ ratio is also considered as one of the important factors for description of overall immune dysfunction and can be used as a better biomarker for disease progression. ${ }^{[50]}$

In the present study, CD4+ count was maintained in both the groups at the end of the study, while CD8+ counts showed a decrease, when compared to baseline. There was a significant increase in this ratio in both the groups in comparison to baseline levels. An important point to highlight here is that the major ingredient of the placebo used in our study was starch. Prior study on starch has suggested its immune boosting effect in management of COVID 19 infection. ${ }^{[51]}$ This supports the positive effects of placebo observed by us in case of few parameters.

Serum IFN- $\gamma$ levels increased on day 30 compared to baseline, but the levels went down on day 60. The placebo group in contrast, showed a decrease on day 30 followed by an increase on day 60 . However, these levels were within normal range as per the studies reported earlier. [52,53] IFN- $\gamma$ is primarily released on the activation of CD4+ cells and is chief 
mediator of innate and adaptive immune response [54]. IFN- $\gamma$ up regulates a variety of pro-inflammatory parameters such as interleukin IL-12, IL-15 and tumor necrosis factor- $\alpha$ (TNF- $\alpha)$. ${ }^{[55]}$ It has also been reported that IFN- $\gamma$ has the potential to direct inflammatory responses by inhibiting production of pro-inflammatory cytokines, IL-1 and IL-8, by upregulating the production of cytokine antagonists such as IL-1Ra and IL18BP.[56]

TNF- $\alpha$ is a pro-inflammatory cytokine which is released in pathogenic conditions. Increased level of TNF- $\alpha$ is indicative of high inflammation in the cell.[57] On the contrary IL-10 is an antiinflammatory cytokine which acts as an antagonist and thereby inhibits the production of pro-inflammatory cytokines, IFN- $\gamma$ and TNF- $\alpha$. [58-61] Our results have shown decreased level of TNF- $\alpha$ from LPS stimulated PBMCs in CIT group on day 60 suggesting less amount of inflammation in cells, while in placebo group, increased levels of TNF- $\alpha$ were seen on day 60 indicative of higher degree of inflammation after stimulation. Though IL-10 levels increased in both the groups, the increase was more evident in CIT group compared to placebo. Thus, by its immune regulatory action, IL 10 did not allow elevation of levels of TNF $\alpha$ in the CIT group compared to placebo on day 60 .

Generation of Reactive oxygen species (ROS) can lead to peroxidation of lipids present inside cells and form products like MDA, which can be quantified to determine the level of oxidative damage to the cell.[62] Studies have suggested that compromised immune functioning can increase ROS production (Reactive Oxygen Species) in RBCs and oxidative stress inside cell[13,14] which can cause an effect on cell integrity, membrane damage and hemolysis of RBSs.[63] Thus, MDA level of biological membranes becomes one of the most studied indicators of oxidative stress. ${ }^{[64]} \mathrm{A}$ decreased level of MDA observed after 60 days of CIT treatment indicates its efficacy to reduce oxidative stress in RBCs. No such trend was observed in placebo group. On the other hand, free radicals deteriorate the immune system, leading to various diseases and early ageing, therefore antioxidants play an important part in cell defence mechanism. Glutathione peroxidase (GPx), is an enzyme which is an integral part of antioxidant system to protect cells from oxidative damage that can be caused by accumulation of hydrogen peroxide.[64] It has been studied for its effect in modulating processes like normal cellular growth and proliferative responses and apoptosis. It is also involved in modulating pro-inflammatory responses.[65] In this study, both CIT and placebo groups showed an increase in levels of GPx on day 60 indicating its antioxidant potential. As mentioned earlier, starch used as placebo has been reported to possess antioxidant properties. ${ }^{[66]}$ Besides, another study by Li. et al on fish fed with starch has shown significantly higher antioxidant potential compared to fish fed with glucose.[67]

It is well known that starch as a component is widely used in formulation of placebo drugs in clinical studies. ${ }^{[68]}$ However, as per our study findings, the placebo drug containing starch was seen to possess an important role in immune function along with antioxidant properties and thus its use as placebo in trials on immunity should be considered with better understanding.

\section{Limitations:}


The up rise of COVID pandemic during the month of March, resulting in subsequent lockdown, interfered with the study conduct. Almost $50 \%$ of study participants could not report to the study site for the follow up visits thereby leading to high attrition.

\section{Conclusion:}

It can be inferred from the results of the study that administration of CIT drug for two months improved immune status and quality of life with a decrease in stress. It was found to be effective in reduction of oxidative stress in the RBCs and enhanced its antioxidant capacity. It thus proved to possess immunomodulatory effect on healthy individuals. However, it still needs a larger sample size and detailed scientific investigations towards $\mathrm{T}$ cell activation and secretory cytokine levels.

Conflicts of interest- The author(s) declare(s) that there is no conflict of interest regarding the publication of this paper

Source of funding: The study has received funding from Charak Pharma Pvt. Ltd.

Acknowledgments: Authors acknowledge administrative support from Director, IRSHA. We thank Ms. Shital Giramkar for her help in standardization of methods used for estimation of different parameters. The authors also acknowledge the sponsor, Charak Pharma Pvt. Ltd.

\section{References:}

1. Narayan R. Encyclopedia of biomedical engineering. Elsevier; 2018 Edition 1.

2. Nicholson LB. The immune system. Essays in biochemistry. 2016;60(3):275-301.

3. Owen JA, Punt J, Stranford SA. Kuby Immunology. New York, NY, USA: WH Freeman; 2013. Edition 7

4. Wu D, Nikbin Meydani S. Age-associated changes in immune function: impact of vitamin E intervention and the underlying mechanisms. Endocrine, Metabolic \& Immune Disorders-Drug Targets (Formerly Current Drug Targets-Immune, Endocrine \& Metabolic Disorders). 2014; 14(4):283-9.

5. Chaplin DD. Overview of the immune response. Journal of Allergy and Clinical Immunology. 2010;125(2):S3-23.

6. Scanlan MJ, Simpson AJ, Old LJ. The cancer/testis genes: review, standardization, and commentary. Cancer Immun. 2004;4(1):1.

7. Lin WW, Karin M. A cytokine-mediated link between innate immunity, inflammation, and cancer. The Journal of clinical investigation. 2007;117(5):1175-83.

8. Patwardhan B, Chavan-Gautam P, Gautam M, Tillu G, Chopra A, Gairola S, Jadhav S. Ayurveda rasayana in prophylaxis of COVID-19. Curr Sci. 2020;118(8):1158-60.

9. Bajaj V, Gadi N, Spihlman AP, Wu SC, Choi CH, Moulton VR. Aging, Immunity, and COVID-19: How Age Influences the Host Immune Response to Coronavirus Infections? Front. Physiol. 2021;11:1-23.

10. Dziedzic T, Slowik A, Szczudlik A. Nosocomial infections and immunity: lesson from brain-injured patients. Crit Care 2004;8:266.

11. Angele MK, Chaudry IH. Surgical trauma and immunosuppression: pathophysiology and potential immunomodulatory approaches. Langenbeck's archives of surgery. 2005;390(4):333-41.

12. Dhabhar FS. Effects of stress on immune function: the good, the bad, and the beautiful. Immunol Res. 2014 May;58(2-3):193-210.

13. Young MR, Wright MA, Lozano Y, Matthews JP, Benefield J, Prechel MM. Mechanisms of immune suppression in patients with head and neck cancer: influence on the immune infiltrate of the cancer. International journal of cancer. 1996;67(3):333-8.

14. Shaw PX, Stiles T, Douglas C, Ho D, Fan W, Du H, Xiao X. Oxidative stress, innate immunity, and agerelated macular degeneration. AIMS molecular science. 2016;3(2):196. 
15. Chen Y, Zhou Z, Min W. Mitochondria, oxidative stress, and innate immunity. Frontiers in Physiology. 2018; 9:1487.

16. Available at https://www.who.int/emergencies/diseases/novel-coronavirus-2019/interactive-timeline. Timeline: WHO's COVID-19 response. Last accessed on 19 ${ }^{\text {th }}$ Aug, 2021.

17. Xi-zhi JG, Thomas PG. New fronts emerge in the influenza cytokine storm. Semin Immunopathol. 2017;39(5):541-550.

18. Li Y, Liu X, Guo L, Li J, Zhong D, Zhang Y, Clarke M, Jin R. Traditional Chinese herbal medicine for treating novel coronavirus (COVID-19) pneumonia: protocol for a systematic review and meta-analysis. Systematic reviews. 2020;9(1):1-6.

19. Rastogi S, Pandey DN, Singh RH. COVID-19 pandemic: A pragmatic plan for ayurveda intervention [published online ahead of print, 2020 Apr 23]. J Ayurveda Integr Med. 2020;S0975-9476(20)30019-X.

20. Available at https://www.mohfw.gov.in/pdf/ImmunityBoostingAYUSHAdvisory.pdf. Ministry of Ayush. Ayurveda's immunity boosting measures for self-care during COVID 19 crisis. Last accessed on $19^{\text {th }}$ Aug, 2021.

21. Philip S, Tom G, Balakrishnan Nair P, Sundaram S, Velikkakathu Vasumathy A. Tinospora cordifolia chloroform extract inhibits LPS-induced inflammation via NF- $\kappa \mathrm{B}$ inactivation in THP-1cells and improves survival in sepsis. BMC Complement Med Ther. 2021;21(1):97.

22. Trinh TA, Park J, Oh JH, Park JS, Lee D, Kim CE, Choi HS, Kim SB, Hwang GS, Koo BA, Kang KS. Effect of Herbal Formulation on Immune Response Enhancement in RAW 264.7 Macrophages. Biomolecules. 2020;10(3):424.

23. Rossol M, Heine H, Meusch U, Quandt D, Klein C, Sweet MJ, Hauschildt S. LPS-induced cytokine production in human monocytes and macrophages. Critical Reviews ${ }^{\mathrm{TM}}$ in Immunology. 2011;31(5).

24. Kalaiselvan S, Rasool MK. Triphala herbal extract suppresses inflammatory responses in LPS-stimulated RAW 264.7 macrophages and adjuvant-induced arthritic rats via inhibition of NF- $\kappa$ B pathway. Journal of Immunotoxicology. 2016;13(4):509-25.

25. Mohan MC, Abhimannue AP, Kumar BP. Modulation of proinflammatory cytokines and enzymes by polyherbal formulation Guggulutiktaka ghritam. J Ayurveda Integr Med. 2021;12(1):13-19.

26. Sharma U, Bala M, Kumar N, Singh B, Munshi RK, Bhalerao S. Immunomodulatory active compounds from Tinospora cordifolia. Journal of Ethnopharmacology. 2012;141(3):918-26.

27. Catanzaro M, Corsini E, Rosini M, Racchi M, Lanni C. Immunomodulators inspired by nature: a review on curcumin and echinacea. Molecules. 2018;23(11):2778.

28. Sawhney R, Berry V, Kumar A. Inhibitory Activity of Rubia cordifolia plant extract against ESBL producing Urinary E. coli isolates. Journal of Pharmacy Research. 2012;5(3):1328-30.

29. Son DJ, Akiba S, Hong JT, Yun YP, Hwang SY, Park YH, Lee SE. Piperine inhibits the activities of platelet cytosolic phospholipase A2 and thromboxane A2 synthase without affecting cyclooxygenase-1 activity: Different mechanisms of action are involved in the inhibition of platelet aggregation and macrophage inflammatory response. Nutrients. 2014;6(8):3336-52.

30. Vaibhav K, Shrivastava P, Javed H, Khan A, Ahmed ME, Tabassum R, Khan MM, Khuwaja G, Islam F, Siddiqui MS, Safhi MM, Islam F. Piperine suppresses cerebral ischemia-reperfusion-induced inflammation through the repression of COX-2, NOS-2, and NF- $\kappa$ B in middle cerebral artery occlusion rat model. Mol Cell Biochem. 2012;367(1-2):73-84.

31. J F Wilod Versprille L, J A E van de Loo A, Mackus M, Arnoldy L, A L Sulzer T, Vermeulen SA, Abdulahad S, Huls H, Baars T, Scholey A, Kraneveld AD, Garssen J, Verster JC. Development and Validation of the Immune Status Questionnaire (ISQ). Int J Environ Res Public Health. 2019;16(23):4743.

32. Baik SH, Fox RS, Mills SD, et al. Reliability and validity of the Perceived Stress Scale-10 in Hispanic Americans with English or Spanish language preference. J Health Psychol. 2019;24(5):628-639.

33. Wong FY, Yang L, Yuen JWM. et al. Assessing quality of life using WHOQOL-BREF: a cross-sectional study on the association between quality of life and neighborhood environmental satisfaction, and the mediating effect of health-related behaviors. BMC Public Health 2018;18:1113.

34. Kanias T, Wong K, Acker JP. Determination of lipid peroxidation in desiccated red blood cells. Cell Preservation Technology. 2007;5(3):165-74.

35. Sly PD, Collins RA, Morgan WJ. Pediatric Respiratory Medicine 2nd ed. Mosby; 2008,Chp 13:pp.171-178. 
36. Motta LP, Silva PPFD, Borguezan BM, et al. An emergency system for monitoring pulse oximetry, peak expiratory flow, and body temperature of patients with COVID-19 at home: Development and preliminary application. PLoS One. 2021;16(3):e0247635.

37. Anastasio F, Barbuto S, Scarnecchia E, Cosma P, Fugagnoli A, Rossi G et al. Medium-term impact of COVID-19 on pulmonary function, functional capacity and quality of life. European Respiratory Journal 2021;58(2).

38. Julio T, Carlos RG, Iván B, Marcelo OH, Israel G, Oscar G et al. Self-Perceived Stress During the Quarantine of COVID-19 Pandemic in Paraguay: An Exploratory Survey. Frontiers in Psychiatry 2020;11:1155

39. Chawla B, Chawla S, Singh H, Jain R, Arora I. Is coronavirus lockdown taking a toll on mental health of medical students? A study using WHOQOL-BREF questionnaire. Journal of Family Medicine and Primary Care. 2020;9(10):5261.

40. França K, Lotti TM. Psycho-Neuro-Endocrine-Immunology: A Psychobiological Concept. Adv Exp Med Biol. 2017;996:123-134.

41. Raony I, Figueiredo CS, Pandolfo P, Araujo EG, Bonfim POS, Savino W. Psycho-Neuroendocrine-Immune Interactions in COVID-19: Potential Impacts on Mental Health. Front. Immunol. 2020;11(1170):1-15.

42. Furman D, Campisi J, Verdin E. et al. Chronic inflammation in the etiology of disease across the life span. Nat Med 2019;25:1822-1832.

43. Korkmaz S, Kazgan A, Çekiç S, Tartar AS, Balcı HN, Atmaca M. The anxiety levels, quality of sleep and life and problem-solving skills in healthcare workers employed in COVID-19 services. Journal of Clinical Neuroscience. 2020;80:131-6.

44. Singh S, Roy D, Sinha K, Parveen S, Sharma G, Joshi G. Impact of COVID-19 and lockdown on mental health of children and adolescents: A narrative review with recommendations. Psychiatry Res. 2020;293:113429.

45. Genta FD, Rodrigues Neto GB, Sunfeld JP, Porto JF, Xavier AD, Moreno CR, Lorenzi-Filho G, Genta PR. COVID-19 pandemic impact on sleep habits, chronotype, and health-related quality of life among high school students: a longitudinal study. Journal of Clinical Sleep Medicine. 2021;17(7):1371-7.

46. Ekkens MJ, Shedlock DJ, Jung E, Troy A, Pearce EL, Shen H, Pearce EJ. Th1 and Th2 cells help CD8 T-cell responses. Infection and immunity. 2007;75(5):2291-6.

47. Kavuma MA, Ejoku J, Ssemogerere L, Lubulwa C, Namata C, Kwizera A, Wabule A, Okello E, Kizito S, Lubikire A, Sendagire C, Andia Biraro I. Association between CD4 T cell counts and the immune status among adult critically ill HIV-negative patients in intensive care units in Uganda. AAS Open Res. 2019;2:2.

48. Cox RJ, Brokstad KA. Not just antibodies: B cells and T cells mediate immunity to COVID-19. Nature Reviews Immunology. 2020;20(10):581-2.

49. Maydych V, Claus M, Dychus N, Ebel M, Damaschke J, Diestel S, et al. (2017) Impact of chronic and acute academic stress on lymphocyte subsets and monocyte function. PLoS ONE 12(11): e0188108.

50. Villar SS, Sainz T, Moreno S. Monitoring the CD4/CD8 ratio: a promising indicator of disease progression in HIV-infected individuals? Future Virology. 2015;10(1):1-4.

51. Mondal D, Singh A, Praveen S, Krishnan V. Resistant starch Could this immunity booster play a positive role in COVID- management? Science Reporter 2020:30-31.

52. Davoodi P, Mahesh PA, Holla AD, Vijayakumar GS, Jayaraj BS, Chandrashekara S, Ramachandra NB. Serum levels of interleukin-13 and interferon-gamma from adult patients with asthma in Mysore. Cytokine. 2012;60(2):431-7.

53. Berktas M, Guducuoglu H, Bozkurt HA, Onbasi KT, Kurtoglu MG, Andic S. Change in serum concentrations of interleukin-2 and interferon- $\gamma$ during treatment of tuberculosis. Journal of international medical research. 2004;32(3):324-30.

54. Vijayaraghava A, Radhika K. Alteration of Interferon Gamma (IFN- $\gamma$ ) in Human Plasma with Graded Physical Activity. Journal of clinical and diagnostic research: JCDR. 2014;8(6): BC05.

55. McNab FW, Ewbank J, Howes A, Moreira-Teixeira L, Martirosyan A, Ghilardi N, Saraiva M, O'Garra A. Type I IFN induces IL-10 production in an IL-27-independent manner and blocks responsiveness to IFN- $\gamma$ for production of IL-12 and bacterial killing in Mycobacterium tuberculosis-infected macrophages. The Journal of Immunology. 2014;193(7):3600-12.

56. Mühl H, Pfeilschifter J. Anti-inflammatory properties of pro-inflammatory interferon- $\gamma$. International immunopharmacology. 2003;3(9):1247-55. 
57. Sethu S, Pushparaj PN, Melendez AJ. Phospholipase D1 mediates TNF $\alpha$-induced inflammation in a murine model of TNF $\alpha$-induced peritonitis. PloS one. 2010;5(5):e10506.

58. O'Garra A, Barrat FJ, Castro AG, Vicari A, Hawrylowicz C. Strategies for use of IL-10 or its antagonists in human disease. Immunological reviews. 2008;223(1):114-31.

59. Hutchins AP, Diez D, Miranda-Saavedra D. The IL-10/STAT3-mediated anti-inflammatory response: recent developments and future challenges. Briefings in functional genomics. 2013;12(6):489-98.

60. Flynn JL, Chan J. Immunology of tuberculosis. Annu Rev Immunol. 2001;19:93-129.

61. Sai Priya VH, Anuradha B, Gaddam SL, Hasnain SE, Murthy KJR, Valluri VL. In Vitro Levels of Interleukin 10 (IL-10) and IL-12 in Response to a Recombinant 32-Kilodalton Antigen of Mycobacterium bovis BCG after Treatment for Tuberculosis Clinical and vaccine immunology. 2009;16(1):111-115.

62. Anderson HL, Brodsky IE, Mangalmurti NS. The evolving erythrocyte: red blood cells as modulators of innate immunity. The Journal of Immunology. 2018;201(5):1343-51.

63. Bogdanska JJ, Korneti P, Todorova B. Erythrocyte superoxide dismutase, glutathione peroxidase and catalase activities in healthy male subjects in Republic of Macedonia. Bratislavske lekarske listy. 2003;104(3):108-14.

64. Battin EE, Brumaghim JL. Antioxidant activity of sulfur and selenium: a review of reactive oxygen species scavenging, glutathione peroxidase, and metal-binding antioxidant mechanisms. Cell biochemistry and biophysics. 2009;55(1):1-23.

65. Day BJ. Catalase and glutathione peroxidase mimics. Biochemical pharmacology. 2009;77(3):285-96.

66. Wen Y, Ye F, Zhu J, Zhao G. Corn starch ferulates with antioxidant properties prepared by N,N'carbonyldiimidazole-mediated grafting procedure. Food Chem. 2016;208:1-9.

67. Han, H., Wang, Z., Wang, J. et al. Impact of high dietary cornstarch level on growth, antioxidant response, and immune status in GIFT tilapia Oreochromis niloticus. Sci Rep 2021;11:1-10.

68. MSD Manual consumer version. Placebos. Available at https://www.msdmanuals.com/enin/home/drugs/overview-of-drugs/placebos. Last accessed on 27 ${ }^{\text {th }}$ August, 2021. 